\title{
Assessment of medical certificate of cause of death at a tertiary care centre in Mumbai, India
}

\author{
Pallavi Uplap ${ }^{1}$, Deepak Wani ${ }^{2 *}$, Lalit Sankhe ${ }^{3}$ \\ ${ }^{1,3}$ Associate Professor, ${ }^{2}$ Medical Officer, ${ }^{1,3}$ Dept. of Community Medicine, ${ }^{1,3}$ Grant Medical College, Mumbai, Maharashtra, District \\ Tuberculosis Centre Palghar, District Palghar, Maharashtra, India
}

*Corresponding Author: Deepak Wani

Email: drwani1980@gmail.com

\begin{abstract}
Introduction: India, the second most populous country in the world shares proportionate global mortality with deficient mortality data. In view of limited literature about quality of cause of death data from our country, a study was undertaken to find out completeness of records of Medical Certificate of Cause of Death (MCCD) and to find out disparity between them and clinical records.

Materials and Methods: A Cross sectional record based study was conducted at a tertiary care hospital in Mumbai. Randomly selected $20 \%$ of records of the patients died after admission to the tertiary care hospital during calendar year of 2016 were included while medicolegal deaths were excluded. Demographic variables, variables related with cause of death were assessed for accuracy and administrative variables were added to these while assessing completeness. The study was conducted after obtaining Institutional Ethical Committee approval and data was analysed appropriately.

Result: All 410(100\%) MCCD forms assessed were notably incomplete and inaccurate. Time interval between mortality causes and death was mentioned in $2(0.48 \%)$ certificates only and that was also inaccurate. Other major errors were mode of dying mentioned as an immediate or antecedent cause of death $353(86 \%)$ and $170(41 \%)$ respectively, multiple causes and use of short forms $229(56 \%)$ and $143(35 \%)$ respectively.

Conclusion: A sustainable training programme with inbuilt quality assurance mechanism for improving medical certification of cause of death at institutional level should be imparted.
\end{abstract}

Keywords: Medical Certificate of Cause of Death (MCCD), Assessment, India.

\section{Introduction}

Mortality statistics remains the cornerstone for planning health services, evaluating health related indicators including emerging and re-emerging diseases. Registration of death is gaining momentum worldwide, due to its importance as a loss of legal identity in the complex structure of modern society. Efficient Civil Registration and Vital Statistics system (CRVS) act as a source of strong population level mortality data on continuous basis as there are limitations to census and survey. Strengthening CRVS has become priority worldwide for reporting against development frameworks such as the Sustainable Developmental Goals (SDGs) where 15 out of the 17 SDGs require CRVS data to measure their indicators. ${ }^{1}$

World Health Organization (WHO) in 1948 introduced a standard format for death certification in order to bring uniformity in this important public health surveillance tool. ${ }^{2}$ Medical Certificate of Cause of Death (MCCD) is the most essential for death registration because of legal, administrative and statistical aspects. ${ }^{3}$ In order to improve quality data of vital statistics including deaths, a guidance tool for a standards-based review of country practices in Civil Registration and Vital Statistics have been developed globally. ${ }^{4}$ About three-fourth $(75 \%)$ of global deaths per year worldwide occur in developing countries.

Globally, completeness and quality of cause of death data was assessed where European Region (EUR) had maximum number of countries with high quality mortality data. In South East Asia Region (SEAR), only four countries were reported where India reported very low quality data $(10 \%){ }^{6}$
At present our country is contributing 9.9 million deaths, nearly $12 \%$ of global deaths with majority of deaths occurring at home due to multiple reasons. ${ }^{7}$ Births, deaths and Marriages Registration Act, 1873 represents age old tradition of vital events. ${ }^{8}$ However it has not much improved vital statistics registration in our country which led to mandatory Central Births and Deaths Registration Act, 1969 and SRS Sample Registration System and Verbal Autopsy. 10

Though legal provisions and guidelines for MCCD are available, they are not percolated uniformlly to issuing authorities. Despite introduction of MCCD, as per the States or Union Territory(UT) wise details of Medical Institutions having in-patient facilities /covered/reporting data on MCCD, out of 77499 medical institutions having inpatient facilities, 51129 are covered under MCCD and out of them only 35761 Medical Institutions reported MCCD data as per the National list for tabulation. During 2015, Maharashtra registered $34.5 \%$ of medically certified death as compared to total registered deaths ${ }^{.11}$ That clearly indicates scope for improving ambit of MCCD in this second most populous state of the country. One of the hindrances to generate robust quality and up-to-date medically certified cause of death data in our country include lack of inbuilt program of reorientation training at the time of induction into medical services. Others are no universal efforts for quality assurance of death certification by government and private health care providers as well as meagre penalty charges against non-compliance of medical practitioners towards statutory provisions mentioned under MCCD. ${ }^{11,12}$ 
India, the second most populous country in the world will be surpassing China by 2022, in terms of population growth with proportionate increase in global mortality. Hence it is definitely a need of the hour to boost the existing death certification mechanism with focus on quality assurance at all level. Published evidence from elsewhere countries supports training interventions improve death certification. $^{13-21}$ In order to achieve this objective multifaceted research with robust monitoring in death certification is crucial. However there is a limited relevant published evidence from our country. ${ }^{15-17,19-21}$ Hence a study was conducted to assess MCCD in a tertiary care hospital in Mumbai. Objectives of same were to find out completeness of death records as well as disparity between clinical records and MCCD.

\section{Materials and Methods}

A Cross sectional record based study was conducted at a tertiary care hospital in Mumbai. For feasibility purpose death records of calendar year 2016 were selected. Among them randomly selected $20 \%$ records of the patients who succumbed to natural death after admission to the tertiary care hospital were included except medicolegal case.

Fourteen variables including demographic and death related details of deceased in MCCD to assess accuracy. In addition to this, signature, name, registration number of Resident Medical Officer and Date of verification were assessed for completeness.
While assessing completeness of MCCDs, for each blank (excluding blank but correct and filled (including blank but correct) variable, score of "0" and "1" scores were given respectively. In this way certificates scoring "17" labelled as completely complete while score of "14-16" as slightly incomplete, MCCDs with score of "7-13" and " $<7$ " were considered as notably incomplete and grossly incomplete respectively. Similarly while assessing accuracy of MCCDs, for each wrongly filled and correctly filled (also includes blank but correct) variable, score of " 0 " and " 1 " scores were given respectively. In this way certificates scoring "14" labelled as completely accurate while score of "11-13" as slightly inaccurate. MCCDs with score of "6-10" and " $<6$ " were considered as notably inaccurate and grossly inaccurate respectively.

Data was collected during June-December 2017 and was entered in Microsoft Excel and analysed appropriately. All necessary permissions including Institutional ethical was obtained.

\section{Results}

During the study period, 3340 deaths took place of which 1288 were medicolegal cases. Analysis of $20 \%$ of 2052 clinically certified deaths was carried out $(n=410)$. It included death records of $159(38 \%)$ female and $251(62 \%)$ male deceased patients.

Assessment of completeness of MCCD was shown as in table number 1 .

Table 1: Assessment of Completeness of Variables in MCCD forms $(n=410)$

\begin{tabular}{|c|c|c|c|}
\hline \multirow{2}{*}{ S. No } & Variables & \multicolumn{2}{|c|}{ Completeness found in MCCD(n=410) } \\
\cline { 3 - 4 } & & No. $(\%)$ & Details of incompleteness No. (\%) \\
\hline 1 & Name of deceased & $409(99.75)$ & $1(0.25)$ \\
\hline 2 & Age & $406(99.02)$ & $4(0.98)$ \\
\hline 3 & Sex & $407(99.26)$ & $3(0.74)$ \\
\hline 4 & Date of admission & $406(99.02)$ & $4(0.98)$ \\
\hline 5 & Date of death & $396(96.58)$ & $14(3.42)$ \\
\hline 6 & Time interval between causes and death & $2(0.48)$ & $408(99.52)$ \\
\hline 7 & Immediate cause of death & $409(99.75)$ & $1(0.25)$ \\
\hline 8 & Antecedent cause of death & $403(98.29)$ & $7(1.71)$ \\
\hline 9 & Underlying cause of death & $375(91.46)$ & $35(8.54)$ \\
\hline 10 & Contributory cause of death & $368(89.75)$ & $42(10.25)$ \\
\hline 11 & Name of Medical officer & $410(100)$ & $0(0)$ \\
\hline 12 & Signature of medical officer & $410(100)$ & $0(0)$ \\
\hline 13 & Registration Number of medical officer & $410(100)$ & $0(0)$ \\
\hline 14 & Manner of death & $410(100)$ & $0(0)$ \\
\hline 15 & Pregnancy in case of female deceased & $0(0)$ & $159(100)$ \\
\hline 16 & If delivered or not & $0(0)$ & $0(0)$ \\
\hline 17 & Date of verification & $410(100)$ & $0(0)$ \\
\hline
\end{tabular}

As seen in table number 1, many variables were incomplete because details were not mentioned.

Level of completeness of MCCD were analysed and mentioned in table 2. 
Table 2: Level of completeness of MCCD forms ( $\mathrm{n}=410)$

\begin{tabular}{|c|c|c|c|c|}
\hline \multicolumn{4}{|c|}{ Completeness of MCCD forms $(\mathbf{n}=\mathbf{4 1 0})$} & \multicolumn{2}{c|}{ Frequency of MCCD forms } \\
\hline Level of completeness & Range of score & Completeness $(\%)$ & No & Percentage \\
\hline Completely complete & 17 & 100 & 0 & 0 \\
\hline Slightly incomplete & $14-16$ & $82-95$ & 0 & 0 \\
\hline Notably incomplete & $7-13$ & $40-76$ & 410 & 100 \\
\hline Grossly incomplete & $<7$ & $<40$ & 0 & 0 \\
\hline Total & & & 410 & \\
\hline
\end{tabular}

Results of Level of accuracy of MCCD were mentioned in table 3.

Table 3: Assessment of Accuracy of Variables in MCCD forms $(\mathrm{n}=410)$

\begin{tabular}{|c|c|c|}
\hline S. No & Variables & No. (\%) \\
\hline 1 & Name of deceased & $361(88.04)$ \\
\hline 2 & Age & $395(96.34)$ \\
\hline 3 & Sex & $404(99.26)$ \\
\hline 4 & Date of admission & $404(98.53)$ \\
\hline 5 & Date of death & $395(96.34)$ \\
\hline 6 & Time Interval between Causes \& Death & $0(0)$ \\
\hline 7 & Immediate Cause of death & $39(9.5)$ \\
\hline 8 & Antecedent Cause of death & $189(46.09)$ \\
\hline 9 & Underlying Cause of death & $241(58.78)$ \\
\hline 10 & Contributory Cause of death & $375(91.46)$ \\
\hline 11 & Manner of Death & $410(100)$ \\
\hline 12 & Pregnancy in case of female deceased & $0(0)$ \\
\hline 13 & If delivered or not & $0(0)$ \\
\hline 14 & How did injury occur? & $0(0)$ \\
\hline
\end{tabular}

Major errors related to accuracy of MCCD were time interval between Causes and Death was not written, mode of dying was mentioned as Immediate, Antecedent and Underlying cause and use of short forms in them.

Following table number 4 shows level of accuracy of MCCD forms

Table 4: Level of Accuracy of MCCD forms $(n=410)$

\begin{tabular}{|c|c|c|c|c|}
\hline \multicolumn{2}{|c|}{ Accuracy of MCCD forms (n=410) } & \multicolumn{2}{c|}{ Frequency of MCCD forms } \\
\hline Level of accuracy & Range of score & Accuracy $(\%)$ & No. & Percentage \\
\hline Completely accurate & 14 & 100 & 0 & 0 \\
\hline Slightly inaccurate & $11-13$ & $78-93$ & 0 & 0 \\
\hline Notably inaccurate & $6-10$ & $40-71$ & 410 & 100 \\
\hline Grossly inaccurate & $<6$ & $<40$ & 0 & 0 \\
\hline Total & & & 410 & \\
\hline
\end{tabular}

\section{Discussion}

During the study period 3340 deaths took place, accounting $6 \%$ against total admissions in that year. The total certified deaths were 2052 and in 1288 cases post mortem was carried out. Analysis of $20 \%$ of clinically certified deaths was carried out.

All death certificates were almost complete as per socio demographic variables as compared to other studies conducted elsewhere. ${ }^{19,22}$

In this study, date of admission and death were mentioned in $406(99.02 \%)$ and $396(96.58 \%)$ respectively in the records assessed while in other studies date of death was mentioned in $99.9 \%$ and $95.9 \%$ records. ${ }^{17,21}$
Completeness of variables such as immediate cause, antecedent cause and underlying were 409(99.75\%), 403(98.29\%) and 375(88.04\%)respectively. In a study conducted in India, the MCCD forms were complete in $99.8 \%, 97.7 \%$ and $98.4 \%$ for variables like immediate cause, antecedent cause and underlying cause respectively while the same were complete in $95.9 \%, 27 \%$ and $1.1 \%$ MCCD forms in another study conducted in India respectively. ${ }^{17,19}$

Time intervals between causes and death were mentioned in only two certificates $(0.48 \%)$ in our study while in other studies in India, it was mentioned in $7.2 \%$ $74.7 \% .^{16,21,23}$

Completeness of MCCD was $100 \%$ as per as variables like Variables like Name of doctor, Signature of doctor, 
Registration Number of doctor and his Designation were considered,equivalent with other study. ${ }^{17}$

In our study, information about important variables like in case of female death, pregnancy status and whether delivered or not, was not available at all. While in a study conducted elsewhere in India, pregnancy status and delivery status were reported in $95.2 \%$ \& $93.5 \%$ respectively. ${ }^{17}$

Overall completeness showed that all certificates were notably incomplete as compared to other study which had used similar kind of grading for assessing completeness, showed majority of certificates were $96.19 \%$ notably incomplete and $73.9 \%$ slightly incomplete. ${ }^{17,19}$

Overall accuracy about socio-demographic information variables varies from $88 \%$ to $98.53 \%$. Major error was in terms of incomplete, wrongly mentioned name in $49(11.95 \%)$ MCCD. Absence or wrong mention of age and sex in $15(3.6 \%)$ and $6(1.4 \%)$ respectively in this study. A similar kind of study conducted at Gujarat revealed $0.2 \%$ and $0.5 \%$ error in name and age respectively while gender accurately mentioned in all certificates while another study observed errors $0.2 \%, 1.26 \%$ and $0.76 \%$ in this respective context in India. ${ }^{17,21}$

In our study, mode of dying was mentioned as immediate cause in $371(90.48 \%)$ certificates and as an antecedent cause and an underlying causes of death in $193(47.07 \%)$ and $17(4.14 \%)$ death records assessed respectively.

In all three causes, 164(40\%) short forms and 266(65\%) multiple causes were mentioned respectively. At $64(15.60 \%)$ places, contributory causes were not mentioned which were mentioned in clinical notes.

Accuracy for immediate, antecedent and underlying cause found to be $39(9.5 \%), 189(46 \%)$ and $241(58.78 \%)$ respectively while other study from elsewhere in the world observed $17.5 \%, 40.8 \%$ and $86.8 \%$ respectively. ${ }^{26}$ Studies conducted elsewhere in India observed $44 \%, 55 \%$ and $69.9 \%$ accuracy respectively and another study observed $95.56 \%, 66.67 \%$ and $40 \%$ accuracy respectively in this context. $17,21,22$

While time interval between immediate antecedent and underlying causes of death and death was mentioned in only $2(0.48 \%)$ records, however it was not accurate $(0 \%)$. However studies conducted elsewhere in India observed $2 \%, 7.9 \%$ and $59.1 \%$ accuracy respectively and another study observed $8.89 \%, 4.45 \%$ and $6.67 \%$ accuracy respectively in this context. ${ }^{17,21}$

Overall accuracy showed that all certificates were notably inaccurate as compared to other study which had used similar kind of grading for assessing accuracy, majority of certificates were notably inaccurate $(57 \%) .{ }^{17}$

\section{Limitations}

The study involved assessment of randomly selected limited number of death records of only one year from a tertiary care hospital in India. Secondly it did not involve assessment of MCCDs in case of medicolegal deaths. Feasibility and time constraints did not permit training interventions for improving quality of cause of death data.

\section{Conclusion}

Findings of the study conclude that there is an urgent need of sensitisation and refresher training for doctors to improve quality of MCCD with a major emphasis on interactive workshops. These training interventions should be backed by a mechanism for appraisal on continued basis.

\section{Acknowledgments}

We thank all the authorities who had given permissions and necessary support to conduct the study.

\section{Conflicts of Interest: None.}

\section{References}

1. Civil Registration and Vital Statistics (CRVS) and the Sustainable Development Goals (SDGs). Available on https://unstats.un.org/unsd/demographic/crvs/Global_CRVS_D ocs/news/CRVS_and_the_SDGs_2016.pdf (accessed on 6/7/2017)

2. World Health Organization. History of the development of the ICD. World Health Organization 2006. Available on www.who.int/classifications/icd/en/HistoryOfICD.pdf(accesse d on $12 / 7 / 2017$ )

3. Medical Certification of Cause of Death-PDF. Available on www.mlam.in/pdf/medicalcertificates/mccd.pdf(accessed on 6/8/2017)

4. Improving the quality and use of birth, death and cause-ofdeath. Available on...www.who.int/healthinfo/tool_cod_2010.pdf (accessed on 9/9/2017)

5. The world health report 2002 - Reducing Risks, Promoting Healthy Life. Available onwww.who.int/whr/2002/(accessed on $12 / 9 / 2017$ )

6. WHO HEALTH STATISTICS 2017- Available on www.who. int/gho/.../world_health_statistics/2017/en (accessed on 16/11/2017)

7. http://www.worldometers.info/world-population/indiapopulation(accessed on 2/1/2018)

8. Park's Textbook of Preventive And Social Medicine-K.PARK $24^{\text {th }}$ edition page $877-78$

9. Central Registration of Birth and Death Act, 1969. Available onwww.pbnrhm.org/docs/b\&d_reg.pdf(accessed on 9/7/2017)

10. Prospective Study of One Million Deaths in India: Rationale, Design...Available on journals.plos.org/ plosmedicinearticle?id=10.1371/ journal.pmed.0030018accessed on 17/7/2017)

11. Annual Report on MCCD-2015 - Census of India. Available on www.censusindia.gov.in/2011Documents/mccd_Report1/MCC D_Report-2015.pdf (accessed on 27/8/2017)

12. Amended uptojuly 2017 - Medical Council Of India. Available on https:// www.mciindia.org/documents/rulesAndRegulations/GME_RE GULATION (accessed on 18/11/2017)

13. Katsakiori PF, Panagiotopoulou EC, Sakellaropoulos GC, Papazafiropoulou A, Kardara M. Errors in death certificates in a rural area of Greece. Rural Remote Health 2007;7(4):822.Available on citeseerx.ist.psu.edu/viewdoc/download?doi=10.1.1.557.8924 \&rep=rep1...pdf(accessed on 29/7/2017)

14. Aung E, Rao C, Walker S. Teaching cause-of-death certification: lessons from international experience. Postgraduate Med J 2010;86(1013):143-52. Available on https://www.ncbi.nlm.nih.gov/pubmed /20237008(accessed on 27/10/2017) 
15. Patel N, Patel S, Vidua RK, Arora A, Tamaria KC. How to evaluate the medical certification of death in a hospital: an analysis of 53 death certificates at AIIMS, Bhopal, India. Int J Community Med Public Health 2017;4(3):797-802.

https://www.researchgate.net/publication/314157329_How_to _evaluate_the_medical_certification_of_death_in_a_hospital_a n_analysis_of_53_death_certificates_at_AIIMS_Bhopal_India (accessed on 2/11/2017)

16. Agarwal SS, Kumar V, Kumar L, Bastia BK, Chavali KH. A study on appraisal of effectiveness of the MCCD scheme. medind.nic.in/jal/t10/i4/jalt10i4p318.pdf(accessed on 23/10/2017)

17. Shah Vr. Evaluation of Medical Certification of Cause of Death in one of the teaching hospitals of Ahmedabad. Innovative J Med Health Sci 2013;2(5). Available on innovative journal. In /index.

php/ijmhs/article/download/453/434(accessed on 19/10/2017)

18. Hazard RH, Chowdhury HR, Adair T, Ansar A, Rahman AQ, Alam $\mathrm{S}$ et al, The quality of medical death certification of cause of death in hospitals in rural Bangladesh: impact of introducing the International Form of Medical Certificate of Cause of Death. BMC Health Servi Res 2017;17(1):688. Available on https://bmchealthservres. biomedcentral. com/articles/10.1186/s12913-017-2628$y($ accessed on 22/10/2017)

19. Ganasva AS, Bariya BR, Shringarpure K, Damor JR. Assesment Of Medical Certificate Of Cause Of Death (MCCD) In Vadodara Municipal Corporation, Gujarat, India. Int J Current Res Rev 2015;7(24):18. Available on ijcrr. com/ uploads/ 371_pdf.pdf(accessed on 5/12/2017)
20. Agarwal SS, Kumar L, Gouda HS, Mestri SC. Medical certification of cause of death. J Indian Academy Forensic Med 2008;30(4):249-52. Available on medind.nic.in/jal/t08/i4/jalt08i4p249.pdf (accessed on 31/10/2017)

21. Jain K, Bala DV, Trivedi K, Chandwani H. Situational analysis of medical certification of cause of death (MCCD) scheme in municipal corporation of Ahmedabad. Indian J Forensic Community Med 2015;2(2):95-9.Available on https://www.Innovativepublication. Com/admin /uploaded.../IJFCM_2(2)_95-99.pdf(accessed on 30/8/2017)

22. El-Nour AE, Mohammed A, Yousif I, Ali AH, Makki M. Evaluation of death certificates in the pediatric hospitals in Khartoum state during 2004. Sudan J Public Health 2007;2(1):29-37.Available on http://citeseerx.ist.psu.edu/viewdoc/download?doi=10.1.1.549. 2748\&rep=rep1\&type=pdf(accessed on 11/11/2017)

23. Gupta N, Bharti B, Singhi S, Kumar P, Thakur JS. Errors in filling WHO death certificate in children: lessons from 1251 death certificates. J Trop Pediatrics 2013;60(1):74-8. https://academic.oup.com/tropej/articlepdf/60/1/74/4643865/f mt059.pdf(accessed on 12/12/2017)

How to cite this article: Uplap $\mathrm{P}$, Wani $\mathrm{D}$, Sankhe $\mathrm{L}$, Assessment of medical certificate of cause of death at a tertiary care centre in Mumbai, India, Indian J Forensic Community Med 2019;6(2):70-4. 